\title{
Historical Session: \\ The Contribution of Amateurs to Astronomy, \\ Yesterday and Today
}

\section{Concluding Remarks}

André Koeckelenbergh

Vice-President, Société Royale Belge d'Astronomie, Méteorologie et Physique du globe, Observatoire Royale de Belgique

Avenue circulaire 3, B-1180 Brussels, Belgium

As I am given the occasion of closing this session, I must not fail to thank and to congratulate Madame Levasseur-Regourd, who presided over the meeting held yesterday. Neither must I fail to give due homage to the amateurs who have made astronomy's history. They are everywhere, and this Colloquium has shown this unequivocally. There are also those who are making astronomy's history today. The marvellous images of the heavens obtained by de Kerolyr delighted me when young, and the long conversations with Boyer and Focas, at Meudon, enriched my experience as an adult.

It would be ingratitude on my part not to recall the meticulous, constant, and disciplined work of some tens of sunspot observers, who send their observations every month to the "Centre de donnés pour les indices de l'activité solaire" (S.I.D.C.). They allow the Wolf number to be rapidly published and passed to organisations concerned with telecommunications, geophysics and space research. This is a field where the simple practicalities of the discipline forces amateur-professional collaboration. Another aspect of this collaboration is participation in expeditions to observe total solar eclipses. Past experience with such events shows that the self-denial and devotion of amateurs are such that many of them are so absorbed in technical tasks, crouching over chromometers and electronics that they often have no chance to view totality and the ephemeral splendour of the corona, which has been the very reason for their having frequently travelled thousands of kilometres, at their own expense!

This is history in the making. I am grateful to all the authors of the notable contributions that we have listened to with such interest over these two days. I also feel the same gratitude towards those who have enabled us to share in this precious common cultural heritage. 